\title{
PERSPECTIVAS FILOSÓFICAS EN TORNO A LA CONSTITUCIÓN CHILENA DE 1980. EL DISPOSITIVO SACRIFICIAL
}

\author{
Carolina LLanos ${ }^{1}$
}

\section{Resumen/Abstract}

El siguiente escrito corresponde a un texto reflexivo que presenta diversos elementos en torno a la Constitución chilena de 1980, que permitirían considerarla como un dispositivo, en sentido foucaultiano, de carácter sacrificial. Para profundizar tal afirmación, se considerarán algunos de sus elementos constitutivos, como su carácter neoliberal y el principio subsidiario subyacente a ella, así como el modo en que estos inciden en la configuración de subjetividades. Se considerará además, una reflexión con vetas genealógicas, que intenta rastrear elementos sacrificiales que estarían operando en su diseño materializado en las ideas de Jaime Guzmán, así como aquellos que influencian a este último, desde el pensamiento de Carl Schmitt.

Palabras claves: Constitución 1980, dispositivo, sacrificio, Carl Schmitt, Jaime Guzmán

\section{PHILOSOPHICAL PERSPECTIVES AROUND THE CHILEAN CONSTITUTION OF 1980. THE} SACRIFICIAL DEVICE

This paper is a reflective text that presents elements about the 1980 Chilean political constitution that would make possible consider it as a sacrificial instrument in a Foucaultian sense. To go in depth with that statement it will be considered some of its constitutive elements, as its neoliberal nature and its underlying subsidiary principle. Additionally, it will be considered a reflection with genealogic aspects that pretend to establish sacrificial elements that would be operating in its materialized design by Jaime Guzmán ideas, just as those that influenced him, from the Carl Schmitt thoughts.

Keywords: 1980 Constitution, instrument, sacrifice, Carl Schmitt, Jaime Guzmán

Pero que no se equivoquen

Los fabricantes de miedos

Ni prisiones ni cadenas

Atemorizan al pueblo

(Jaime Soto, Julio Rojas)

${ }^{1}$ Chilena, Universidad de Chile. E-mail: carolinallanos@ug.uchile.cl 


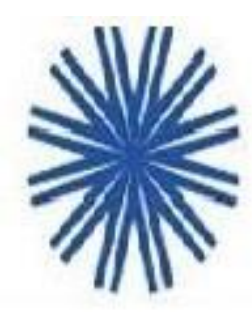

Preliminares: la política, la constitución y la vida de las personas

Para acceder a la protección social, que desde la Organización Internacional del Trabajo (OIT) se ha considerado como el Derecho Humano a la seguridad social, en Chile se debe demostrar que se es pobre. Esta situación, que desmiente la idea de que la seguridad social es un instrumento de justicia social, se complejiza aún más, cuando se considera que las políticas relacionadas con el cumplimiento de los derechos constitucionales, ya no enfocadas a situaciones de protección, sino que a aquellas que se relacionan con la producción y reproducción de la vida; se desarrollan en el mismo nivel de precariedad. Tal elemento resulta revelador, en cuanto pone de manifiesto al menos tres aspectos acerca del modo de hacer política que se ha dado en el país durante los últimos cuarenta años, que impacta directamente la vida de las personas.

En primer lugar, está el hecho por todos constatable, acerca de cómo los derechos se condicionan a la situación económica de los sujetos, es decir, que hay una primacía del ámbito económico por sobre el campo de lo político, que tal como aquí se desarrollará, ocurre al amparo de lo jurídico ${ }^{2}$. En segundo lugar, tras la afirmación anterior, se deja ver que quién debe demostrar su condición material "económica" mediante instrumentos de focalización ${ }^{3}$, para la obtención de algún "beneficio”, son los pobres, mientras que la clase adinerada no debe rendir cuentas acerca de su capital, avalándose así, una desigualdad extrema, indigna y violenta, en la medida que el pobre debe relatar una y otra vez su situación, introyectando en su subjetividad, su condición de pobreza. Finalmente, lo que se deja entrever considerando los aspectos antes señalados, es que en Chile opera un gestión de la pobreza y de la vida de las personas desde un sistema de "(in)seguridad social”, lo que es fiel reflejo de una "economización" de la política en términos neoliberales y de una praxis que va de la soberanía al gobierno en sentido foucaultiano (Foucault 2006: 100).

Ahora bien, si se considera que tales situaciones responden a un comportamiento sistemático por parte de la clase política, que ejerce desde una racionalidad neoliberal específica, donde uno pudiese señalar que esta precarización de la vida se manifiesta como un elemento estructural de la organización político-social, la tarea ineludible se dirige hacia la consideración acerca de cuáles son aquellos mecanismos que sostienen

\footnotetext{
${ }^{2}$ Esto se observa con claridad en las enunciaciones recogidas en las Actas del Coloquio Lipman.

${ }^{3}$ Refiero principalmente al Registro social de hogares, recientemente muy cuestionado por distintos grupos sociales.
} 
tal situación, donde uno de los más relevantes se materializa en la sujeción jurídica que mantiene la constitución vigente. Desde tal perspectiva, la relevancia en torno al debate constitucional se hace evidente, no únicamente en términos de un análisis que se mueva en el ámbito jurídico político y las posibilidades de una asamblea constituyente, sino que considerando la perspectiva filosófica que subyace a estas dimensiones, sustentándolas y reafirmándolas, así como también, modelando la vida de las personas, mediante la incidencia en su comportamiento y en la configuración de sus subjetividades.

En el siguiente ensayo, se desarrollará una reflexión en torno a la idea que señala a la constitución chilena de 1980 como un dispositivo neoliberal, de carácter ficcional, que amparado en la noción de libertad, encubre una violencia sacrificial, que en razón de sus diversas transfiguraciones y mediante la implementación de discursos específicos, particularmente los meritocráticos y patriarcales, logra grabarse profundamente en la vida de los chilenos al día de hoy.

A lo largo del texto se considerará tal dispositivo en sentido foucaultiano, entendido como un entramado o conjunto de instituciones, leyes, relaciones y discursos, que en su permanente interacción, operan como un sistema complejo de relaciones capaz de instaurar un régimen de veredicción que mediante el disciplinamiento del cuerpo y de las subjetividades, logra normalizar a un conjunto de sujetos según formas de actuación específicas (Foucault 2006). Si bien Foucault no proporciona una definición unívoca acerca de lo que considera dispositivo, en tanto su propuesta filosófica es fragmentaria a consecuencia de su positividad (Castro 2008), es preciso señalar aquí que el dispositivo no se materializa únicamente en las instituciones, sino más bien en una diversidad de elementos que, por una parte, implican un sistema de contenidos basados en la relación saber-poder y, por otra, logra una efectiva incidencia en el campo social, tanto en el género como en la especie, ámbitos en los que puede situarse la Constitución de 1980.

\section{Perspectivas sobre discusiones en torno a la Constitución de 1980}

Según la abogada y premio Tribunal constitucional 2008-2009, Tania Busch, el conjunto de críticas a la Carta Magna de 1980, puede comprenderse como una doctrina crítica a la Constitución Chilena, que se materializa principalmente en la concreción de tres ejes a discutir (2012). El primero de ellos se relaciona con el origen ilegítimo y autoritario en que fue elaborada la Constitución (Busch 2012; Atria 2013; Bassa 2020), entendiendo que su diseño se elabora en contexto de dictadura y relegada a la Comisión Ortúzar. Una segunda línea que reúne otro grupo de críticas, corresponde al hecho de que la misma, consagra un 
régimen poco democrático, tanto porque la concepción de democracia incluida originalmente en el texto, no se concreta, lo que se observa en la poca participación ciudadana, así como también porque protege un determinado modelo social, que considera a la democracia como un medio de estabilización y no como un fin (Busch 2012). Esto ha sido expresado por distintos autores, por ejemplo como dictadura constitucional (Moulián 1998), democracia protegida mediante cerrojos (Atria 2013), de carácter gatopardista en la perspectiva de Ruiz Tagle (2017): cuanto más cambia, más se reafirman los mismos elementos, como una constitución celda, que aparenta ser democrática, pero que limita la agencia política (Suárez en Busch 2012). Con matices, todas estas perspectivas críticas aluden, a la preservación reforzada de un modelo, tal como veremos más adelante, desde una perspectiva inmunizadora, donde pareciese que lo jurídico, además de ser un instrumento para poner en marcha un proyecto político, opera como una neutralización de la agencia política del pueblo.

Una tercera línea crítica más cercana a un debate ideológico, se enmarca en la explicitación de que la Constitución chilena de 1980, se constituye como un hito relevante para el establecimiento de un sistema neoliberal, con un marcado déficit en los derechos económicos y sociales (Bassa 2008; 2020). En esta tercera lectura, también se erige a una crítica de legitimidad de la Carta Magna, ya no desde su origen, sino que en la medida que no logra responder a las demandas que van surgiendo desde la ciudadanía.

En cuanto a la legitimidad de la Constitución, Atria también acentúa los matices diferenciales respecto de la ilegitimidad de origen, en sentido procedimental y en cuanto a su contenido o elemento sustancial, que posibilitaría o no el ejercicio político. A partir de esto, aunque hubiese continuidad respecto del contenido entre las Constitución de 1925 y 1980, habría una ruptura radical, en cuanto la última modificaría la forma de dictarse a partir de una decisión, que anula la heteronomía del pueblo (2013). Con lo que resulta entonces factible, afirmar que la Constitución de 1980, es ilegítima debido a su origen, pero también sustancialmente, en cuanto impide al pueblo, el apropiarse de ella.

La distinción sobre la legitimidad, sea de origen o en su proceso de aplicación, puede complementarse además con la mirada de Hernán Molina Guaita (1998) quien diferencia entre un enfoque estático y uno dinámico, donde existe "una legitimidad estática, que mira al origen de la Constitución; y una legitimidad dinámica, que se refiere a la aplicación de la Constitución en el tiempo" (34) donde ambos elementos 
deben considerase. No obstante, en tal perspectiva, nuevamente se evidenciaría la necesidad de reconocer que la legitimidad de la constitución se ha agotado.

Ahora bien, resulta relevante considerar además de estas líneas de encuadre, que las posibles miradas en torno a las discusiones constitucionales están muy matizadas según filiación política, donde llaman la atención, las críticas emanadas de la derecha chilena. Existen, según García-Huidobro (2020), al menos cuatro perspectivas de abordaje, donde la derecha coincide en concentrarse en elementos de carácter formal o de diseño constitucional (Ortúzar, 2020), evitando el componente ideológico como ocurre en el caso de Mansuy o Herrera (2020), mientras que la izquierda estaría apostando por aproximarse al debate desde discursos con focalización en una narrativa contestataria de carácter retórica y en clave ideológica.

Una primera posición desde la derecha, sería aquella que reconoce el desgaste del actual sistema político mostrándose abiertos a la posibilidad de una nueva constitución, pero salvando la tradición constitucional (Fontaine, 2018) y por ello oponiéndose a comenzar desde lo que se ha llamado "hoja en blanco" en cuanto representaría una especie de "negacionismo"; no obstante, para posturas contrarias, esta correspondería justamente a la posibilidad de comenzar desde el discernimiento político y no histórico, en cuanto una nueva constitución no estaría atada a otras decisiones (Atria 2013:11). Por otra parte, habría un sector de la derecha que no estaría de acuerdo con una nueva constitución, puesto que reconocerían en ella legitimidad de ejercicio, en tanto su vigencia alcanza 30 años, además de haber sido reformada en numerosas oportunidades, por lo que ya no se estaría en condición de afirmar que ella sigue teniendo la ilegitimidad de origen criticada. Esta perspectiva se apoya en la idea de "rechazar para reformar"; no obstante en términos concretos, se evidencia su debilidad argumentativa en la medida que la mayoría de los cambios demandados por la ciudadanía encuentran barreras que los señalan como "inconstitucionales".

Mientras que la centroizquierda aparece con una perspectiva más distante respecto de la discusión constitucional, un enfoque distinto respecto de los señalados anteriormente, sería aquel abordado por el Frente Amplio y el partido Comunista, quienes en la perspectiva de García-Huidobro (2020) estarían quitando relevancia a los elementos de diseño, y por consecuencia generando propuestas débiles, en cuanto discursivamente enfatizan el reposicionamiento de un ethos democrático. 
Ahora bien, ¿qué es lo que hay tras la discusión en torno a la legitimidad de la Constitución y a las diversas posturas aparentemente opuestas que han surgido en torno a tal debate? Pensar que tales diálogos pueden desarrollarse sin mirar el componente ideológico o sólo considerando el diseño constitucional, parece reductivista e ingenuo. Una importante reflexión que puede darse en perspectiva filosófica es justamente aquella que, desde el punto de vista genealógico, tiene la capacidad de desentrañar los elementos que están operando en tales configuraciones de sentido, como un modo de iluminar las reflexiones actuales. Considerando esto, es posible identificar los componentes estructurales de la Constitución del 1980, no en clave jurídica, si no que más bien desde su despliegue en una especie de análisis experiencial. De esta manera, si se propone a la Constitución de 1980 como un dispositivo sacrificial que, además de asumir su no legitimidad, busca entender cómo a partir de ella, la ciudadanía se ve permeada por discursos, instituciones y elementos jurídicos que moldean su subjetividad bajo una lógica de constantes sacrificios para pertenecer a una comunidad. Si se menciona la noción de libertad contenida en la Constitución, así como la idea de un sujeto empresarial imbricado con el principio de subsidiariedad, es justamente para señalar cómo, quienes vivimos normados desde la Constitución de 1980, vamos permeándonos de esa violencia sacrificial expresada en la naturalización de un autoritarismo patriarcal y de una lógica meritocrática que nos exige comportamientos específicos, ante la ausencia o debilitamiento de derechos sociales.

Distanciándose de miradas provenientes de la derecha y considerando que la ilegitimidad de la Constitución hoy se da en los tres ejes señalados inicialmente, el que aquí se presenta es retrospectivo, en vistas de complementar el debate constitucional actual con una mirada filosófica acerca de la estructura de la excepción en clave sacrificial.

El carácter neoliberal de la constitución de 1980 y el principio de subsidiariedad: elementos para una estructura sacrificial

La racionalidad neoliberal corresponde a una forma de concebir el mundo que posibilita el gobierno de sí y de los otros (Estupiñan 2016) que se caracteriza por ser diversa y móvil, además de presentar una sorprendente capacidad de reformulación respecto de la situación contextual en la que se desenvuelve, aspecto relevante en cuanto podría representar uno de los motivos, entre otros, de la profundidad con que se arraiga y de su permanencia en el tiempo. De esta manera, tal razón neoliberal es del todo hegemonizante, en tanto se posiciona como una totalidad respecto de otros posibles modos de organización, capturando cualquier desviación de lo que esa razón codifica. Tanto la razón neoliberal 
como la idea de un estado subsidiario, no se encuentran presentes en el texto constitucional de modo literal, pero claramente pueden inferirse del análisis de sus artículos escritos en la parte llamada “dogmática”, por ejemplo: “Artículo $1^{\circ}$ Las personas nacen libres e iguales en dignidad y derechos. 2 La familia es el núcleo fundamental de la sociedad. El Estado reconoce y ampara a los grupos intermedios a través de los cuales se organiza y estructura la sociedad y les garantiza la adecuada autonomía para cumplir sus propios fines específicos” (Constitución Política de Chile, 1980)

Tal como señala el profesor Rodrigo Karmy (2016), el artículo primero de la actual constitución se devela profundamente dogmático, a lo que añado el componente ideológico, en cuanto tiene a la base la afirmación acerca de un conjunto de atributos que desde la modernidad, han operado como un elemento de cohesión social, pero que como hoy vemos, se revelan ficcionales; tal es el caso de valores como la "libertad" y la "igualdad" en dignidad.

Para la racionalidad neoliberal, la libertad puede entenderse rastreando su versión liberal, que por una parte encuentra asidero en la filosofía de Hobbes, que la señala como una no interferencia donde la libertad dependería en gran medida del "silencio de la ley", pero también en consideración de aquellas perspectivas que "aceptan" una interferencia de la ley, para precisamente preservarla (Cristi y Ruiz-Tagle 2006:20). A partir de nociones como aquellas, poco a poco se va preparando el camino para su total enaltecimiento y desplazamiento, donde su núcleo neoliberal se encuentra en autores como Hayek, quien toma distancia del pensamiento clásico.

Este presenta su perspectiva desde una filosofía de la libertad, elevándola a visión de mundo, lo que le permite situar a la economía como paradigma de una época, mediante una actualización de la crítica kantiana, que planteándose las posibilidades y limitaciones de la razón y la libertad aplicada al libre mercado, delimita a esta última como un elemento que ya no compete únicamente a los derechos civiles de los ciudadanos, sino que a partir de su consideración "racional", permite un desplazamiento de la atribución de la libertad del humano hacia el dinamismo económico que no resulte artificioso. En tanto la libertad no surge de la naturaleza, puesto que el paradigma de la modernidad opera desde una voluntad de dominio sobre ella, hay desplazamiento del potencial creador antes atribuido al ámbito natural o religioso, que ahora se antropologiza. 
La libertad entonces no corresponde a un estado de la naturaleza, ni a una trascendencia, sino que a una producción que es posible lograr mediante el decurso de la historia; es casi un producto de la civilización, que en el caso de Hayek, al ser articulada con la razón, "ensamblan su racionalidad teológicogubernamental" (Karmy 2016:57). El hecho de vincular la libertad con la racionalidad constituye el punto de inflexión para que una razón examinadora pueda sostener sin limitar, un régimen de libertad, en clave teológica en el sentido de Schmitt. Esto ocurre en plena concordancia con la visión de la política moderna, donde "La dialéctica característica de la política moderna que divide el mundo entre "amigos y enemigos" de un Estado, se subsume a la nueva dialéctica entre los "amigos y "enemigos" de la libertad" (Karmy 2016:59) y donde la libertad se vincula directamente con la propiedad privada y lo monetario.

La libertad ya no solo le compete al individuo aislado, sino que al elevarse a una razón de mundo y a otros elementos acerca de los cuales ella también puede predicarse al mercado, y la libertad de éste último se acrecienta y la del individuo disminuye, aunque la primera necesite de la segunda para posicionarse como tal, en tanto los derechos están permeados por la libertad de elección, la cual tiene a la base una dicotomía excluyente o una gama de posibilidades que quizá no contienen lo que las personas quieren tomar por opción. En ese sentido, lo que se ha planteado por libertad se revela como una ficción, en tanto la ambigüedad neoliberal que hay en torno a ella, es justamente la promoción de una libertad de los individuos en el discurso, que disfraza un individualismo radical, basado en una visión empresarial de los sujetos, en concordancia con una visón de libre mercado.

Con mucha razón señala Atria que "El neoliberalismo tiene continuidad con el liberalismo, pero solo en el plano de las ideas. En el plano de las oposiciones concretas, es su opuesto. Y son las segundas, no las primeras, las que identifican políticamente" (Atria y Sepúlveda 2016: 7). A lo que añadiría el hecho de que, lo que eventualmente pudiese ocurrir en el plano de las ideas, se da en la forma de un progresivo vaciamiento de ellas para posteriormente, dotarlas de un nuevo contenido, donde únicamente se conservan las ventajas, que en un momento dado reportó el liberalismo, a partir de lo nominal y de lo que políticamente dejaba atrás. En ese sentido la continuidad es forzosa pero ocurre, y se materializa en el hecho de que todos se autodenominan "liberales" y muy extrañamente alguien se identifica como neoliberal (Atria y Sepúlveda 2016: 6). 
Es relevante precisar que esta concepción de la libertad en Hayek no sería posible sin la noción de orden espontáneo, donde lo que se busca demostrar no es el cálculo y predicción de esa racionalidad, sino que justamente que ella no puede predecirse pero sí establecer modos de control en cuanto a los flujos con que se desarrolla. En concordancia con lo señalado por el profesor Karmy, el paradigma político-estatal y su soberanía a partir del estado de excepción, habría sufrido un desplazamiento hacia el paradigma económico-gestional bajo la nueva figuración de la libertad (2016: 56). Ahora hay un orden espontáneo sin un centro específico - la misma lógica foucaultiana de descentramiento del poder- que reemplaza a la excepción y compete a los individuos, en tanto se conciben desde la capacidad de acción que se concreta en el éxito, dando lugar al sujeto empresarial. A partir de esto ocurre que: "La "libertad" está dentro y fuera a la vez de la razón, como la economía lo está respecto de la ley. En ello reside su soberanía” (Karmy, 2016: 73).

Esto es relevante porque una forma de pensamiento que se acentúa en la modernidad, puede reconocerse en el pensamiento que se da a partir de "pares" de conceptos, de dualismos arraigados desde el pensamiento antiguo, pero considerados ahora con una cualidad diferente, puesto que son ordenados en una jerarquía, evidenciando cada vez una supremacía o dominio de uno sobre el otro (ya no con el énfasis agonal o el de la mentalidad griega), donde el juego que se da entre ambos, corresponde justamente al lugar o no-lugar, más precisamente el interregno, que posibilita nuevas articulaciones para pensar una pos política.

Solo para ejemplificar como opera el entramado libertad-razón en tanto paradigma económico-gestional que produce sujetos empresariales, relataré algunos hitos específicos sobre política pública en torno a vivienda. Posteriormente a 1952, cuando se realiza el primer censo de la vivienda en Chile, que evidencia la magnitud del problema habitacional, se crea la primera política nacional de vivienda que al no tener respaldo financiero por parte del gobierno de Ibáñez, ni tampoco un respaldo empresarial, en tanto no es viable invertir para pobres porque representa un riesgo económico, tal iniciativa fracasa. De esta forma, se genera un ambiente propicio para el fortalecimiento y la intervención del empresariado de la construcción, de orientación democratacristiana, influidos por la doctrina social de la iglesia y de formación en la Universidad Católica, quienes acogen visiones como las de Merrell, que hablan de una "racionalidad económica productivista" en materias de vivienda (Cofré 2019). Esta progresión de hitos y asentamiento de ideas, aunque enunciadas laxamente, me parece relevante, porque evidencia en primer 
lugar, como se va instalando la racionalidad neoliberal que posteriormente se institucionaliza en la Constitución de 1980, con la no garantía del derecho a la vivienda.

En segundo lugar, tales hechos expresan la presencia de un estado débil, ante la capacidad de articulación del sector empresarial, o que no es débil pero sí funcional a la lógica mercantil, lo que va en la línea de la subsidiariedad antes mencionada. Finalmente, me parece relevante que la ausencia de una política nacional de la vivienda cohesionada, que trascienda los diferentes gobiernos y el fortalecimiento de la construcción en vivienda desde el empresariado, sumado a la creación del DFL2 en el 1959, contribuyen a que los sujetos, específicamente las familias, orienten sus acciones a lo que se conoció como "el sueño de la casa propia", donde mediante créditos podían acceder "libremente" a la propiedad, pero desde un disciplinamiento donde se debe trabajar mes a mes para demostrar una efectiva capacidad de ahorro y así acceder al "beneficio" social. Es importante notar que tales políticas y créditos como el DFL2, desde su diseño, se orientan a un tipo específico de sujetos, aquellos que pueden trabajar y producir, quienes no son en extremo pobres, sino aquellos que evidencian una gestión "empresarial de sí” y que fácilmente pueden ser normalizados en el sentido de Foucault (2006: 64).

Aquí hay un primer atisbo de cómo se moldea una subjetividad, en función de las leyes, los créditos y un discurso meritocrático transfigurado, que ya no se dirige a los políticos gobernantes, sino que al ciudadano común, en tanto él es libre para conseguir lo que quiera desde el esfuerzo, puede trabajar para hacerlo, ya que no se regala nada porque las cosas se consiguen con trabajo y él debe sacrificarse para obtenerlo por sus méritos, y más aún, si cuenta con una familia a la que debe proveer, con lo que se ve a "el sujeto empresario" y "los grupos intermedios" de la sociedad, operando tal como se señaló en la cita del artículo $2^{\circ}$ de la Constitución.

En ese sentido es que puede afirmarse que la constitución, además de establecerse como un dispositivo de racionalidad neoliberal, necesita de ficciones como la "libertad", que posibilita una autoexplotación en beneficio del capital, que se ejerce de un modo sumamente diferente a la manera como trabajan las clases adineradas y que, por consiguiente, se relaciona también con la ficción de la "igualdad”. Es en la articulación de estas ficciones de la razón neoliberal como saber-poder y en su materialización en la Constitución de 1980, donde subyace la noción de sacrificio, en el sentido de una institución social diferente a como se consideraba en la Antigüedad y el Medioevo, no como un elemento que contiene o 
canaliza la violencia, al modo de Girard (1995), sino que como un elemento que sutiliza y diversifica esa violencia, transfigurándola y complejizándola, en cuanto se manifiesta como un elemento implícito en la dimensión contractual de la vida en comunidad, en el sentido de que: "la comunidad está ligada al sacrificio de la compensatio, mientras que la inmunitas implica el beneficio de la dispensatio" (Esposito 2012:30).

El sacrificio como institución social en su dimensión positiva, considerado como darse a una comunidad o don; o en su dimensión negativa, entendido como pérdida, explotación, residuo o vaciamiento de la subjetividad, adquiere una tonalidad distinta a sus manifestaciones precedentes, puesto que "la modernidad se afirma separándose violentamente de un orden cuyos beneficios no parecen ya compensar los riesgos que comportan, como las dos caras indisolublemente unidas con el concepto de munus: don y obligación, beneficio y prestación, conjunción y amenaza" (Esposito 2012: 40). Entonces, el hecho de que el beneficio no se condice con el riesgo o el esfuerzo para alcanzarlo, implica que el sentido de ambas dimensiones de lo comunitario se modifica para dar paso a la radicalización de uno de ellos, donde en el caso del sacrificio como don/obligación, se percibe como pérdida o expropiación de la subjetividad (Esposito 2005:92).

Con la finalidad de reforzar la idea de una subsidiariedad que debilita los derechos y que potencia el vaciamiento de la subjetividad del sujeto empresarial en la actual constitución, quisiera explicitar que ella aparece también en los artículos vinculados a la educación, que es atribuida como primera responsabilidad a los padres ${ }^{4}$, y que según el profesor Retamal (2013) constituye la mayor perversión de Guzmán, en cuanto, por una parte, privatiza la educación y respalda con ello la desigualdad, pero, por otra, modela subjetividades direccionándolas hacia una despolitización radical de los sujetos, como otro enclave de la constitución, operando en términos de Esposito, como una estrategia de inmunización.

El principio de subsidiariedad se reconoce también, en el derecho a la salud, donde lo que se resguarda y garantiza es la posibilidad de elegir entre un sistema de atención de salud público o privado, pero no el acceso a ella. Como señala Matías Goyenechea (2019), esto categoriza distintos tipo de sujetos según sus

\footnotetext{
${ }^{4}$ Ver Constitución chilena 1980, “40/ 10․ "El derecho a la educación. La educación tiene por objeto el pleno desarrollo de la persona en las distintas etapas de su vida. Los padres tienen el derecho preferente y el deber de educar a sus hijos. Corresponderá al Estado otorgar especial protección al ejercicio de este derecho."
} 
posibilidades acceso a la atención pública ${ }^{5}$ o privada, y en caso de ser público, nuevamente según categorías de FONASA A, B, C y D.

La libertad en sentido neoliberal y la pretensión de igualdad en conjunción con el Estado subsidiario, que limita los derechos fundamentales, operan como un dispositivo donde libertad e igualdad constituyen relatos ficcionales que comportan un tipo de violencia que consiste en hacer de algo que no es, devenir otra cosa, una especie de transfiguración mediante un saber que justifica su posición. Esto es justamente lo que está en marcha desde la institucionalización de la Constitución de 1980, una voluntad de señorío que se posiciona como "uno"/"amo", como poseedor de una racionalidad que es "la" correcta para el gobierno del mundo, delimitando y distribuyendo flujos de poderes, ahogando toda posibilidad de heterogeneidad y pluralismo, así como también, configurando la totalidad de lo real, dotando de sentido cada valor y concepto utilizado para explicar el mundo. Y esto lo consigue, asumiendo el poder desde un paradigma pastoral, en la medida que para la autoconstrucción se necesita construir a los “otros" como aquellos que no saben gobernarse y necesitan ser gobernados. Para Jaime Guzmán, él es quien sabe cómo preservar el bien común y por ello el más capacitado para destruir e implementar una nueva institucionalidad, mientras que el pueblo aparece como incapaz de reconocer lo que es mejor para sí, por lo que no puede ser portador de poder constituyente.

Esta tecnología del yo, que introyecta en la subjetividad del otro su "no saber", su "no capacidad de representación" y "no capacidad de auto gobierno o agencia", constituye una violencia estructural y epistémica manifiesta en el discurso en la forma de un permanente ataque a la subjetividad, que resulta posible en contextos de despolitización por parte del pueblo, en concordancia con una politización extrema y focalizada en un grupo reducido, el de las élites que concentran el capital. Dicho inversamente y al modo como lo señala el profesor Karmy, a través de una economización de la política, que se percibe como situada en aquellos grupos de poder conformados por familias que concentran el capital en Chile. No es extraño reconocer que este paradigma económico-gestional se perciba como una despolitización por los sectores más pobres y como una economización de la política en los sectores con mayores recursos

\footnotetext{
${ }^{5}$ Ver Constitución Chilena de 1980, 9: "El derecho a la protección de la salud. El Estado protege el libre e igualitario acceso a las acciones de promoción, protección y recuperación de la salud y de rehabilitación del individuo. Le corresponderá, asimismo, la coordinación y control de las acciones relacionadas con la salud. Es deber preferente del Estado garantizar la ejecución de las acciones de salud, sea que se presten a través de instituciones públicas o privadas, en la forma y condiciones que determine la ley, la que podrá establecer cotizaciones obligatorias. Cada persona tendrá el derecho a elegir el sistema de salud al que desee acogerse, sea éste estatal o privado.”
} 
económicos o intelectuales, ya que pueden estar operando como expresiones diversas de un mismo fenómeno y del lugar donde uno esté situado.

Así como la razón está supeditada a la libertad en Hayek, y por consecuencia el Estado a la economía, hay articulaciones donde la política queda supeditada al derecho. Esto es relevante de considerar para ir comprendiendo cómo el elemento jurídico materializado en la Constitución de 1980, constituye a ésta como un dispositivo de la racionalidad neoliberal, que al amparo del ámbito jurídico, contiene una violencia originaria o "mítica” en el en sentido de Benjamin (1998).

\section{Carl Schmitt y el dispositivo sacrificial}

Tener presente el pensamiento de Carl Schmitt, resulta entonces relevante al considerar el debate constitucional en Chile, porque aborda el problema del poder constituyente y la soberanía, pero por sobre todo, porque sus ideas son recepcionadas e implementadas por Jaime Guzmán ${ }^{6}$, permitiéndole a este último, por ejemplo, legitimar la dictadura. Si bien, en los textos aquí abordados, correspondientes a Teología Política, La dictadura y Teoría de la constitución, no se reconoce una alusión directa acerca de un componente sacrificial en su pensamiento, me parece que efectivamente es posible reconocer elementos que dan cuenta de la puesta en marcha de tal componente.

Si el elemento sacrificial se expresa en la relación entre ley y violencia como señala Benjamin, es importante considerar en el caso de Schmitt, que la decisión soberana es aquella capaz de decidir sobre el Estado de Excepción por una parte, y el modo como tal soberanía es conferida, por otra. A partir de esto, habría que al menos detenerse en la capacidad de dar forma de ese poder soberano.

Hay en Schmitt, un permanente juego de fuerzas en disputa donde una parte intenta instaurar derecho, y la otra, pretende conservarlo, en un conflicto que no se resuelve sino que se sostiene. En el texto $L a$ dictadura (1985) esto se expresa en el dualismo de un poder constituyente y un poder constituido, que en Teología Política (2009), se expresa como una soberanía que se define por tener la capacidad de decidir sobre el Estado de Excepción, donde la estructura de esa excepcionalidad, en la forma de una analogía estructural, se posiciona como componente teológico que define lo político en la modernidad. Estado de

\footnotetext{
${ }^{6}$ Desde la perspectiva de Cristi, Guzmán si habría estado influenciado por Schmitt, desde la perspectiva de Gazmuri, esto no es seguro, pero sí Guzmán si habría estado bajo el influjo autoritario de Donoso Cortés.
} 
Excepción, refiere a la situación en que un Estado de Derecho, es decir, concebido dentro del campo jurídico, tiene la capacidad de levantar un contexto excepcional caracterizado porque justamente se retrotrae de lo jurídico, liberándose de la normativa. Es decir que: "La existencia del Estado deja en este punto acreditada su superioridad sobre la validez de la norma jurídica. La decisión se libera de todas las trabas normativas y se torna absoluta en sentido propio. Ante un caso excepcional, el Estado suspende el derecho por virtud del derecho a la propia conservación” (Schmitt 2009: 18).

En otras palabras, el Estado utiliza la lógica sacrificial de suspender momentáneamente el derecho, en función del beneficio propio. La estructura de la excepción es relevante, porque al tratarse de una lógica o modo de proceder de lo estatal respecto de lo jurídico, lo que está en juego corresponde más bien a la forma en que esto se operativiza, antes que a la substancia o el contenido, donde esa acción soberana, capaz de determinar la excepción, es jurídica aún, pese a su retirada, y por ello mismo, es capaz de conferirse autoridad. Dice Schmitt: "El caso excepcional transparenta de la manera más luminosa la esencia de la autoridad del Estado. Vemos que en tal caso la decisión se separa de la norma jurídica y, si se nos permite la paradoja, la autoridad demuestra que para crear derecho no necesita tener derecho" (2009: 18). Es claro entonces, como la soberanía le compete a "quien decide sobre el Estado de excepción" (13), donde tal decisión constituye también, la capacidad de dar forma política a la vida de un pueblo, a partir de su representación, que en Schmitt es jerárquica y existencial.

Soberanía es el poder de decidir quién dentro de esa jerarquía es el enemigo, teniendo además la capacidad de fundar un nuevo orden. Este elemento autoritario en el momento fundacional, aunque Schmitt no lo enuncie así, es el elemento portador de una violencia sacrificial. Esto se explica en Benjamin, a partir de lo que él señala como violencia mítica, donde la violencia aparece como elemento constitutivo de las relaciones sociales de derecho y al mismo tiempo de la historia, al punto de que la violencia interviene, incluso en los casos más favorables, en toda relación de derecho, como verdad fundadora o conservadora del mismo: "no existe igualdad, en el mejor de los casos violencias igualmente grandes" (1998:40), donde esa violencia fundante es sacrificial en tanto se ejerce en contra de un grupo y en beneficio de otro.

Entonces, para Schmitt, hay una idea jurídica del derecho, que corresponde a una forma jurídica, donde aquello que la define, es la indeterminación y justamente por eso, comporta una necesidad de realización para expresarse en el mundo empírico en la forma de un orden concreto. Es justamente ahí, donde se 
necesita al Estado como un poder legítimo que admite el momento de positividad del derecho, mediante un acto de decisión soberana, es decir, que el derecho necesita al estado para ser ley, sin estar el Estado subordinado a ella, ya que "si el Estado se rebaja al papel de simple pregonero del derecho no puede ser soberano" (Schmitt 2009: 27); donde esa decisión por una forma u orden concreto, corresponde a un momento puramente jurídico, con lo que el caso excepcional muestra la autoridad del Estado, ya que por decisión, se separa de la norma jurídica, dice Schmitt "los racionalistas no deberían perder de vista que el mismo orden jurídico puede prever el caso excepcional y suspenderse a sí mismo” (2009: 19).

En la Teología política entonces, hay una idea de la soberanía de corte autoritario en tanto fundamentación de ella misma sin recurrir a una norma externa, al mismo tiempo que la mejor forma, corresponde según Schmitt, al principio católico de la representación, que posteriormente con el Nomos en la tierra, genera una apertura hacia una situación post política en tanto se pone en evidencia la crisis del carácter katechóntico de lo político, con el advenimiento del nihilismo entendido como época de las neutralizaciones políticas y la emancipación a escala global de la libertad y la técnica (Karmy 2000).

Sobre el decisionismo de Schmitt, es relevante considerar que siempre hay un poder soberano o constituyente que funciona como una voluntad. Al haber decisión y no contractualismo, por ejemplo, el orden obedece a una decisión política fundamental y por consiguiente emerge de una desigualdad constitutiva, donde el componente sacrificial es exacerbado en tanto punto de partida enteramente ficcional y no pactado, y que al ser jerárquico, en representación de la forma dualista católica, avanza en base a la subordinación de otros elementos, donde ese carácter fundacional de la decisión, vendría de la “identidad más alta” dada por un poder originario de mandar. Ese poder, es portador de una violencia originaria, que al no ser como las otras, sino que superior y legítima en tanto es capaz de dar forma, constituye una violencia formal, en tanto presupone que un pueblo carece de forma, abriendo así la trampa topológica de la soberanía, en tanto ella es política y jurídica a la vez y mientras que no puede reducirse a cada una de ellas, ni tampoco escindirse de ambas (Karmy 2009). En tal perspectiva, se sitúa la dicotomía decisión/pueblo, que será heredada por Guzmán.

Si lo sacrificial consiste entonces en una imposición autoritaria de una parte sobre otra, en Carl Schmitt, podemos reconocer que la lógica de la excepcionalidad opera para ello en concordancia con la analogía estructural presente en la política moderna, en tanto "todos los conceptos de la moderna Teoría del Estado 
son conceptos teológicos secularizados" (2009: 37), donde la capacidad de dar forma a un pueblo, adquiere primacía en su expresión católico-romana, mediante un autoritarismo que fundamenta una decisión soberana. Es decir, el poder constituyente concentrado en la autoridad y no en el pueblo, donde en esta atribución perfectamente puede estar operando la ficción de una autoridad fundada en un plano metafísico, como una idea trascendental, que se utiliza para dar forma a un pueblo, que acentúe el elemento sacrificial y la perspectiva inmunizante, que justamente ponen en evidencia la fragilidad de la vida ante la dimensión jurídica.

\section{Jaime Guzmán y la institucionalización de la violencia sacrificial}

Renato Cristi, en su libro El pensamiento político de Jaime Guzmán Una biografía intelectual (2011), caracteriza a este último como el "autor intelectual de la dictadura, y en ese sentido, un pensador revolucionario" (13). Tal descripción le es atribuida en la medida que justamente Guzmán, logra "destruir" la Constitución de 1925, para fundar una nueva institucionalidad a partir del texto constitucional de 1980, en el sentido soberano de Schmitt, mediante la estrategia de "elaborar un evento fundante de un nuevo orden social y político que corregía el curso histórico que, en la segunda mitad del siglo XX, había tomado Chile" (Ibid.).

Luego de los antecedentes aquí presentados, podemos reconstruir la idea de que en la Constitución de 1980 está operando el elemento sacrificial, que puede leerse particularmente en las ideas de a) una concepción del gobierno bajo el paradigma pastoral antes señalado, b) el autoritarismo y su conjunción con el valor de la libertad entendido como la capacidad de dar "forma" en sentido schmittiano, con c) la legitimación de una dictadura soberana, y finalmente en d) la consolidación del neoliberalismo a partir de la noción de sujeto desde la concepción de la prioridad ontológica y la finalidad de los individuos de corte tomista. Todo esto reforzado por la implementación de la propaganda de agitación y de integración (Durán 1995: 13), a través de escritos en revistas teóricas de la derecha chilena (Cristi y Ruiz 2015: 103-121) y particularmente en el diario El Mercurio.

A partir de Cristi, es factible reconocer una extensa producción intelectual de Jaime Guzmán, en la que es posible diferenciar en tres períodos: una primera etapa marcada por la elección del presidente Frei en 1964, donde intenta conjugar mediante la complexio opositorum las nociones de autoridad y libertad; un segundo momento marcado por el golpe militar al gobierno de Allende en el 1973, donde se aboca a la 
construcción de la nueva institucionalidad; y finalmente un tercer momento, marcado por la puesta en vigencia en septiembre de 1980, de una nueva constitución, donde elabora una concepción de democracia que intenta armonizar con los principios autoritarios y libertarios (Cristi 2011: 19-23). Estas etapas encuentran continuidad en su crítica al comunitarismo lo que resulta posible, en gran medida, debido a su temprana adhesión a la tradición conservadora chilena.

Para una visón más o menos panorámica y general, es relevante considerar que el conjunto de su pensamiento, está influido por diversos elementos como por ejemplo, el neoliberalismo de Hayek y la influencia de los Chicago Boys, el tomismo, el corporativismo, el decisionismo de Schmitt y Donoso Cortés, además del Carlismo. Guzmán no se reconoce como liberal, pero sí como franquista -aunque según Gazmuri (2013), posteriormente se desmarca de tal perspectiva- y se reconoce también como gremialista.

La presuposición del pueblo como una masa incapaz de autogobernarse, evidencia la necesidad de articular forma y materia para Guzmán, puesto que el orden de las sociedades no es dado ni auto originado, en tanto que "los individuos son imperfectos, es decir, tienen percepciones irrevocablemente parciales y subjetivas del bien común. En segundo lugar, todo orden social dejado a su suerte es inestable" (Cristi 2011: 87), con lo que la intervención se justifica y desde Guzmán, resulta completamente factible atribuir el poder constituyente a la junta militar, a partir de la concepción schmittiana del poder constituyente, en tanto "no se constituye como una dictadura comisaria sino soberana" (Cristi 2011: 101), todo en vistas de preservar el orden y el bien común, sobre todo porque la democracia no es considerada como un fin en sí misma sino que un instrumento para lograr ese "bien común", dirigida a un conjunto de individuos atomizados.

Así, Guzmán sostiene que la constitución de 1925 se había agotado (Cristi 201: 100) y por ello surge la necesidad de una nueva institucionalidad. Aquí se desarrolla y aplica la dimensión katechóntica del pensamiento de Schmitt, de corte inmunizadora según Esposito, que procede según la forma de construir a otro como enemigo y posicionarse como aquel que tiene la razón, fabricando enclaves que protejan a la constitución de su adversario, mediante la capacidad de dar forma política, fundando un nuevo orden basado en una jerarquía, donde el punto máximo recae en un autoridad, que al igual que en Schmitt, 
implica un componente metafísico o un meta contenido (Karmy 2009), acompañado de la implementación de discursos, que ponen énfasis en el enemigo.

La consolidación del neoliberalismo basado en la prioridad ontológica y la finalidad de los individuos, puede reconocerse en la Declaración de principios del gobierno de Chile, proclamada el 11 de septiembre de 1974, donde se refleja la nueva institucionalidad proyectada por Guzmán, mediante afirmaciones como: “igualdad ante la ley y una moral del mérito y el esfuerzo personal” (Cristi 2011: 51) donde "el ciudadano público debe ceder paso al individuo privado que solo atiende sus asuntos familiares, vecinales y gremiales (51). Influenciado por la ontología tomista, Guzmán llega a afirmar que "tanto del punto de vista del ser como desde el punto de vista del fin, el hombre es superior al Estado" (52), pero en la actual constitución se establece a la familia como núcleo de la sociedad. El hecho de por qué la constitución señala tal afirmación, puede tener relación con el autoritarismo que quiere justificar una jerarquía, dada por la secuencia de autoridad-individuo-familia-Estado, en una especie de degradación de los entes, entendidos como seres accidentales de relación, respecto de un ser superior, donde el individuo encarna lo más sustancial en la tierra, lo más cercano a esa autoridad, pero donde ocurre que la familia concentra la propiedad privada y por ello tiene un mayor peso en el contexto de un paradigma económico-gestional, lo que se refleja en la redacción del Artículo $1^{\circ}$ de la Constitución.

Hay una especie de sacrificio de la sociabilidad, de lo comunitario, en beneficio del individuo, que alcanza una justificación metafísica. Esto puede ser una forma de esconder el radical individualismo, así como de potenciar al mismo tiempo, un tipo de familia nuclear, patriarcal y hétero-normada, que invisibilice el trabajo reproductivo y potencie el productivo, y con ello la movilidad del capital. Esto por ejemplo, se concreta en situaciones como en el hecho de que los puntajes asignados por el Registro Social de Hogares, puntúa menor a las familias y más aún a las madres solteras, para acceder a los "beneficios" sociales, premiándolas, incentivándolas, en tanto a menor puntaje, mayor posibilidad de obtención de beneficios. Por otra parte, la familia es el punto intermedio entre el individuo y el Estado, lo que permite una mayor cohesión social de estos dos elementos funcionales a la economía neoliberal, puesto que si se situase solo al individuo como base de la sociedad, en tanto no presenta mayor vinculación, el neoliberalismo evidenciaría su debilidad como sistema social atomizado, por lo que Guzmán no puede mostrar el individualismo a la base. Según Cristi, en Guzmán "lo social es un accidente, pero un accidente necesario" (2011: 91). Al mismo tiempo, esta forma de concebir al individuo le sirve para sustentar la noción de 
libertad que posibilita el entendimiento de la propiedad como un derecho real, posibilitando el hecho de que constitucionalmente, lo derechos fundamentales, queden subsumidos a los derechos de propiedad. Así como la libertad era importante para Guzmán, se ha de considerar que ella debía darse en un contexto ordenado y autoritario, tal como en algún momento lo señaló Portales, según Edwards, en el sentido de que "la técnica constitucional le importaba poco: lo esencial, en su concepto, era arreglar lo que él llamaba el resorte principal de la máquina, esto es el gobierno impersonal, obedecido y respetado, superior a los partidos y prestigios personales" (Gazmuri 2013: 82). Así opera la amalgama de valores libertadautoridad, donde el primero es atribuido al libre mercado y el segundo a un estado fuerte, no por su presencia, si no que justamente por que jurídicamente ampara el libre mercado para la preservación del bien común.

Como elemento final de este apartado y como aspecto que contribuye a la instalación de un enemigo del pueblo chileno, quisiera referir a la propaganda de agitación que tantos efectos logró en la propagación de ideas funcionales al establecimiento de una nueva institucionalidad. Pienso que su fortaleza radica fundamentalmente, en abordar elementos vinculados a la emocionalidad y la psique del pueblo, como una contrapartida y complemento de la racionalidad neoliberal antes mencionada. De esta manera, el abordaje de la subjetividad de los chilenos durante la dictadura cívico-militar y durante la creación de la Constitución de 1980 y el periodo de "transición" a la democracia, es total, puesto que hunde sus raíces en la espiritualidad de un pueblo, en el alma o en la nación en la perspectiva de Góngora (1981). Según Claudio Durán: “se entiende por propaganda de agitación en este escrito una específica y sutil asociación entre violencia del marxismo y la imagen angustiosa del mundo. Este concepto se utiliza para englobar aspectos de la realidad que son en sí mismos angustiosos, sin referencia política, por ejemplo, la delincuencia, los accidentes, las catástrofes naturales" (1995: 16) y en esta dirección, señala el autor, que cuando Allende está en el poder, hasta 1973, la propaganda desarrollada en el diario El Mercurio es de agitación, mientras que posterior al golpe militar, la propaganda es de "integración" es decir, de conformidad con un orden existente, donde el objetivo consiste en estabilizar el cuerpo social.

Como señala Ruiz (Cristi y Ruiz: 2014), ya en la década de 1960 hay una gran influencia del neoliberalismo en los economistas de la Universidad Católica, a través de un convenio suscrito con la Universidad de Chicago, y quienes en 1967 comienzan a editar la "Página Económica” de El Mercurio. Al mismo tiempo se crea la revista Polémica económica social, la revista Portada y Qué Pasa (105). Todo 
esto colabora con la difusión del corporativismo y el neoliberalismo desde una amplia producción en torno al conocimiento y la propaganda, posibilitando su expresión ideológica. En palabras de Tomás Moulian (1998), un componente esencial de la dictadura cívico-militar es el miedo, el terror, que expresa la supremacía de la misma en la "poderosa aliación entre poder normativo y jurídico, poder sobre los cuerpos (terror) y poder sobre las mentes (saber). Pero si se analiza a fondo esta estructura, lo que tiene peso decisivo es el terror, ya que es el fundamento de la soberanía absoluta del despotismo y es capaz de acallar la soberbia del saber" (22). Con lo que el diseño para el manejo de las subjetividades se completa.

\section{Consideraciones finales}

En Chile pasamos de una dictadura del terror a una dictadura constitucional señala Moulian, para referir a cómo la transición a la democracia, implicaba avanzar con elementos autoritarios, ahora justificados constitucionalmente bajo la figura de la democracia protegida. Esto resultó posible, porque Jaime Guzmán, con el afán de intentar proteger la configuración de poder que subyace a la Constitución de 1980, construye diversos enclaves que le quitan el poder constituyente al pueblo, en tanto "había que pensar en el bien común a mediano y largo plazo" (109).

Si bien, en la historia de la elaboración de las constituciones en Chile no se ha dado el caso de que sea el pueblo quien ejerce soberanía, en la Constitución de 1980 operan elementos consientes que reafirman esta posición de poder, puesto que para Guzmán, el pueblo es un peligro del que hay que protegerse. Estos enclaves constitucionales, o cerrojos en los términos de Atria (2013), corresponden a los altos quórum para modificar leyes, el sistema electoral binominal, y el control preventivo del tribunal constitucional. A estos elementos que inmunizan al neoliberalismo contra la democracia, puede agregarse la despolitización que se instala constitucionalmente, específicamente en la educación, como un modo de anular el pensamiento crítico, y finalmente, el manejo de las subjetividades mediante la fabricación del miedo como elementos extra constitucionales que contribuyen a la paralización de los sujetos. Lo interesante, es que si uno proyectara la lógica de Guzmán, aquella que señala que cuando una constitución se agota, exige la elaboración de una nueva, podríamos decir que estamos en un momento crucial para aquello. Claramente, lo que interesa no es seguir la perspectiva de Guzmán, sino que mostrar cómo cada uno de esos enclaves se fueron desmoronando con el tiempo. Hoy ya no contamos con el sistema electoral binominal y los estudiantes de nuestro país han cambiado y, ya sea con mayor o menor organización política, han tenido la capacidad de irrumpir en la escena pública evidenciando las complejidades de la LOCE, reactivando el 
movimiento social el 2006, el 2011 y recientemente en el octubre chileno del 2019, así, pareciera que el miedo también desaparece y las ideas que defienden los derechos fundamentales se afirman.

La Constitución chilena del 1980 se ha agotado porque evidentemente tiene un origen ilegítimo y porque no se relaciona con la realidad del país, en tanto su contenido se ha develado ficcional y no cohesiona ni representa la identidad política del país; pero se ha agotado también, porque existen derechos garantizados en una normativa internacional que son fundamentales y que no están amparados en ella, lo que evidencia la tremenda inconsistencia local-global. Por otra parte, ya no resulta posible pensar que el ejercicio de la soberanía quede reducido a una democracia formal mediante la elección por "plebiscitos y elecciones periódicas" como señala el artículo $5^{\circ}$ de la constitución de 1980. Su deslegitimación tiene múltiples abordajes.

A partir de estas reflexiones es posible afirmar que los derechos fundamentales, como por ejemplo los de la salud, educación y vivienda aquí mencionados, no son garantizados, más bien, se han suspendido o sacrificado en favor de la economía neoliberal. Tal situación rebaja su estatus de derecho y obliga a los ciudadanos a luchar por ellos, con lo que se pueblan de sentido las palabras de Uribe cuando señala que Chile es el país más legalista de la región, donde “el país nació y vivió en la violencia y fue aprendiendo que ella era necesaria y que debía ser justificada en la ley” (2001), con lo que se devela la violencia naturalizada en la vida de los chilenos, evidenciando el diseño a la base que la sustenta. Se hace necesario ahora mantener toda la fuerza destituyente para los procesos que se avecinan y trabajar por la potencia constituyente. Ya se verá lo que sucede.

\section{Referencias bibliográficas}

Atria F. (2013), La Constitución tramposa. Santiago: Lom ediciones.

Atria F., Sepúlveda C. (2016), Liberalismo, neoliberalismo y socialismo. En Revista TRAMA. Santiago: Metales pesados ediciones.

Bassa J. (2020), Chile decide por una nueva Constitución. Santiago: editorial Planeta.

Bassa J., Viera C. (2008), Contradicciones de los fundamentos teóricos de la Constitución chilena con el Estado constitucional: notas para su reinterpretación. En Revista de Derecho. Vol XXI, N², 131-150. 
Benjamín W. (1998), Para una crítica de la violencia y otros ensayos. Madrid: Taurus.

Brito, S. (2020). Por una constitución feminista. Santiago: Libros del pez espiral.

Busch T. (2012), El concepto de Constitución y la incomodidad constitucional en Chile. Topics, Vol. 12, N². Artículo 5, DOI: https://doi.org/10.1515/1934-2640.1410

Castro E. (2008), Biopolítica de la soberanía al gobierno. En Revista Latinoamericana de Filosofía, Vol. XXXIV N², 187-205.

https://www.academia.edu/35199627/Biopol\%C3\%ADtica_de_la_soberan\%C3\%ADa_al_gobierno

Cofré B. (2019), La vivienda en Chile: un estudio sobre los empresarios y sectores medios para una nueva perspectiva de análisis. Fundación FEMAN, equipo de investigación INVEDUC.

https://fundacionfeman.cl/wp-content/uploads/2019/08/vivienda-en-chile-empresarios-sec-mediosboris.pdf

Cristi R. (2011), El pensamiento político de Jaime Guzmán Una biografía intelectual. Santiago: Lom ediciones.

Cristi R. \& Ruiz C. (2015), El pensamiento conservador en Chile seis ensayos. Santiago: Editorial Universitaria.

Cristi R. \& Ruiz-Tagle P. (2006), La República en Chile Teoría y práctica del Constitucionalismo Republicano. Santiago: Lom ediciones.

Durán C. (1995), El Mercurio Ideología y propaganda 1954-1994. Ensayo 1 Propaganda de agitación en el período de agosto 1972 - marzo 1973. Santiago: Ediciones Chile y América CESOC.

Escalante F. (2018), Así empezó todo. Orígenes del neoliberalismo Las Actas del Coloquio Lipman. Documento único, extraordinario y esclarecedor acerca del origen del neoliberalismo en el mundo. México D.C.: editorial Cal y arena.

Esposito R. (2005), Inmunitas Protección y negación de la vida. Buenos Aires: Amorrortoru editores. (2012), Comunitas Origen y destino de la comunidad. Buenos Aires: Amorrortoru editores.

Estupiñan M. (2016), El ABC del neoliberalismo. Viña del mar: Asociación Communes.

Fontaine A. (2018), ¿Por qué no retomar la Constitución de 1925? En 1925 Continuidad republicana y legitimidad constitucional: una propuesta. Santiago: Ed. Catalonia.

Foucault M. (1993), La microfísica del poder. Madrid: Ediciones La piqueta.

Foucault M. (2006), Seguridad, territorio y población (1977-1978). Buenos Aires: Fondo de cultura económica.

Gazmuri, C. (2013), ¿Quién era Jaime Guzmán? Santiago: Ril editores. 
Girard R. (1985), La violencia y lo sagrado. Barcelona: Anagrama.

Góngora M. (1981), Ensayo histórico sobre la noción de Estado en Chile en los siglos XIX y XX. Santiago: Ediciones La Ciudad.

García-Huidobro L. (2020), Las batallas por la Constitución chilena. En CIPER académico https://www.ciperchile.cl/2020/08/31/las-batallas-por-la-constitucion-chilena/

Goyenechea M. (2019), Estado subsidiario, segmentación y desigualdad en el sistema de salud chileno. En Revista Cuadernos Médico Sociales. Vol. 59 (2), pp. 7-12.

Herrera H. (1998), La comprensión constituyente. En 1925 Continuidad republicana y legitimidad constitucional: una propuesta. Santiago: Ed. Catalonia.

Karmy, R. (2005), Violencia mítica y vida desnuda en W. Benjamin. En A parte Rei: Revista de filosofía, n³9, pp. 1-17. http://serbal.pntic.mec.es/ cmunoz11/karmy39.pdf

(2009), Carl Schmitt y la política del Anti-cristo. Raëpresentation, forma política y nihilismo. En Revista Pléyade, n³, pp. 25-52.

http://www.revistapleyade.cl/wp-content/uploads/02.-Karmy-Carl-Schmitt-Y-La-Politica-Del-

AntiCristo.pdf

Molina H. (1998), Derecho constitucional. Concepción: Universidad de Concepción.

Moulián T. (1998), Chile actual Anatomía de un mito. Santiago: Lom ediciones.

Ortúzar P. (2020), Carta a la tía Pikachu. Instituto de estudios de la sociedad IES. https://www.ieschile.cl/2020/10/carta-a-la-tia-pikachu/

Retamal J. (2013), Nos siguen pegando abajo: Jaime Guzmán, dictadura, concertación y alianza: 40 años de educación de mercado. Santiago: Ceibo ediciones.

Schmitt, C. (1985), La dictadura desde los comienzos del pensamiento moderno de la soberanía hasta la lucha de clases proletaria. Madrid: Alianza editorial.

Trotta.

(2009), Teología política cuatro capítulos sobre la doctrina de la soberanía. Madrid: Editorial

Uribe A. (2001), El fantasma de la sinrazón y el secreto de la poesía. Editorial Arce. 